\title{
INNOVATIVE TECHNOLOGIES AND EDUCATION Two Successful Case-studies
}

\author{
Nicoletta Di Blas, Paolo Paolini and Aldo Torrebruno \\ HOC-LAB, Politecnico di Milano, Piazza Leonardo da Vinci 32, 20133 Milano, Italy
}

Keywords: Innovative Learning Experiences, Collaborative Learning, 3D Multi-user Environments, Digital Storytelling, Edutainment, Evaluation, Case-study.

\begin{abstract}
When "going digital" in the field of education one possible option - typically adopted in higher and adult education - is, so to speak, to "enhance the real world" through technology. Course materials are provided in digital format, face-to-face interaction is replaced by forums or social spaces, exercises and activities are remotely performed and scored, etc. Another option is to create "innovative learning experiences", that without technology would not be possible nor conceivable. Innovative learning experiences are more difficult to conceive, and also riskier to introduce in an established learning environment: they are also more difficult to explain and to evaluate. Innovative learning experiences, however, have also a great potential: they can generate "excitement" (something new!) and non-traditional educational benefits (still alongside with the 'traditional' ones), like increased media literacy, professional skills and attitudes and more. In this paper, we will present two real-life innovative learning experiences for schools: collaborative 3D environments (for high school students) and digital storytelling (for pupils of all school grades, including kindergarten). We will discuss how they were designed and deployed (involving more than 20,000 students, from 3 continents) and what educational benefits they brought about.
\end{abstract}

\section{INTRODUCTION}

When designing an eLearning experience, there are basically two options: one is to try to enhance with technology a "traditional" activity, the other is to use technology to create something totally new. The first option is usually taken in higher or adult education. Course materials are provided in digital form by means of a platform, people taking part in the course share materials, exchange ideas, comments and questions via forums and social spaces, assignments are given, performed and scored in electronic form etc. Technology provides the way all the above activities are done, but the activities per se remain basically the same as they are in the real world and are only slightly affected by the new medium. Many universities around the world (like MIT, for example;

http://ocw.mit.edu/OcwWeb/web/home/home/index. htm), offer online courses of this kind or make available digital content.

But new technologies offer potentially infinite new ways to re-interpret the teaching/learning process and many examples are 'out there' to show that advanced, creative, innovative projects can be successfully introduced in the field of education, at all levels. Quest Atlantis (Barab et al., 2009) and Wolf Quest (Schaller, D. et al., 2009), are just some of them. Sasha Barab of Quest Atlantis well expresses the idea behind these experiences: "the games we design offer something new to learners; unlike any other form of curriculum, these games offer entire worlds in which learners are central, important participants; a place where the actions of a ten-year old can have significant impact on the world; and a place in which what you know is directly related to what you are able to do and, ultimately, who you become." (www.questatlantis.org). In this paper we will present two real-life examples of this kind of approach: (1) a set of blended learning programs based on collaborative 3D environments and (2) a digital storytelling tool for allowing schools (of all grades) to produce their own multimedia narratives. Both programs have been developed and deployed by our lab and have involved a huge number of participants $(20,000$ on the whole, from 3 continents). The educational experiences in the

Di Blas N., Paolini P. and Torrebruno A. (2010).

INNOVATIVE TECHNOLOGIES AND EDUCATION - Two Successful Case-studies.

In Proceedings of the 2nd International Conference on Computer Supported Education, pages 341-348

Copyright (C) SciTePress 


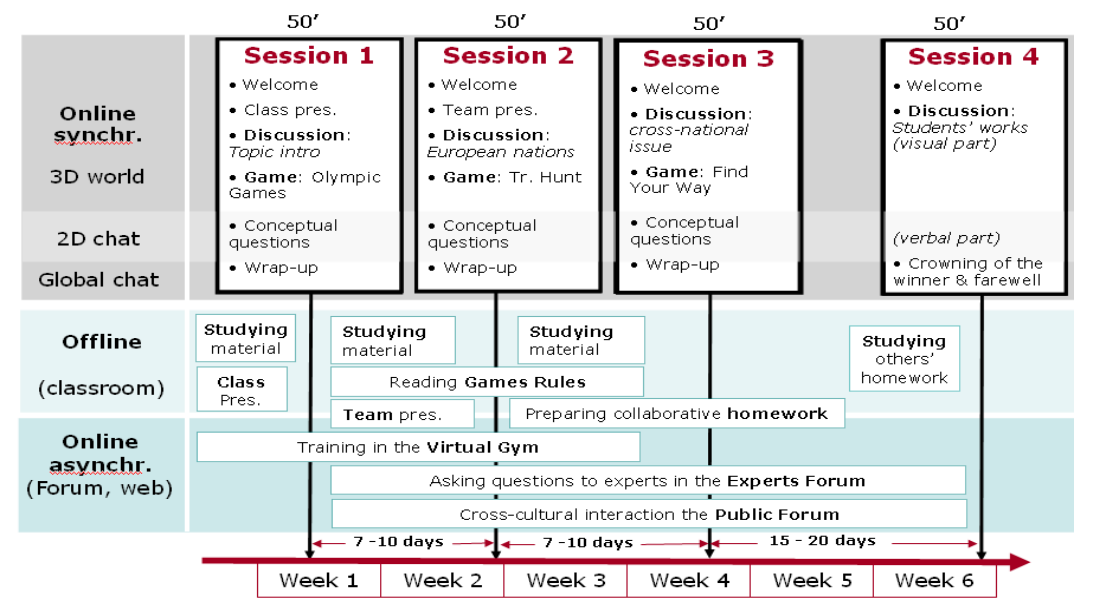

Figure 1: The Learning@Europe project's overall ‘storyboard' of the activities.

collaborative virtual environments offer a highly structured set of activities while the storytelling activity is more open-handed. Both programs share the same high rate of success in providing substantial educational benefits of various kinds that go beyond the 'traditional' ones.

\section{CASE 1: COLLABORATIVE 3D ENVIRONMENTS}

Since 1999, HOC-LAB has developed and deployed educational experiences based on collaborative 3D environments, with various partners and on various subjects, involving more than 9,000 students from 18 different European countries plus Israel and USA.

- 1999: Virtual Leonardo, in cooperation with the Museum of Science and Technology "Leonardo da Vinci" of Milan (Italy).

- 2002-04: SEE (Shrine Educational Experiences). In cooperation with the Israel Museum, on the "Dead Sea Scrolls" and related religious, historical, sociological issues (www.seequmran.net).

- 2004-06: Stori@Lombardia. In cooperation with the regional government of Lombardy (Italy), on the medieval history of the Lombardy region (www.storialombardia.it).

- 2004-08: Learning@Europe. In cooperation with Accenture International Foundation, on the formation of European identities (www.learningateurope.net). In year 2007, a special edition was held in cooperation with the American Military Academy of West Point, on a comparison between European and American history.

- From 2007: Learning@ SocialSport. In cooperation with Fondazione Italiana Accenture, VerdeSport (of the famous Italian fashion brand Benetton) and CONI (the Italian Olympic Committee) on ethical, sociological and psychological issues related to sport (www.learningatsocialsport.net).

All the above are blended learning experiences, interleaving ICT-based activities (the most prominent of which are interactive sessions in a shared 3D environment) with normal school activities. A key point (from the beginning) was to provide a highly structured experience: we wanted participants to pursue meaningful, involving tasks that would keep motivation high (for a discussion on how to design a 3D-based educational experience see Di Blas, Garzotto, Poggi, 2009). Therefore we sketched and refined over the years a 'storyboard' both of the experience as a whole and of each online session (that were managed by online tutors). Figure 1 shows the most advanced version of the storyboard, the one that was used in the Learning@Europe project from year 2007.

\subsection{How the Activity Works}

Students taking part in one of the above programs are supposed to perform a number of activities. The core of the experience are four online meetings in a collaborative 3D environments where, under the guidance of an online tutor, students take part in games (fig. 2), answer quizzes, discuss and also share content like pictures of their countries and self-presentations (fig. 3). 


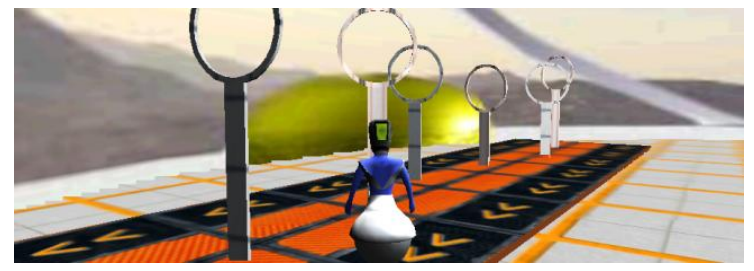

Figure 2: Learning@Europe. An avatar tries its luck in the "Olympic Games", flying through circles. In the collaborative environments cultural discussions alternate with games, giving vent to an 'edutainment' experience.

In between these meetings, they are required to study background materials and complete assignments. Even these activities - that are in a certain sense typical for school - are re-interpreted in an innovative way: background materials are in the form of lively interviews to European experts, often displaying different points of view over the same issue (thus fostering the development of critical thinking in the students); assignments are cooperative, in the sense that they must be completed together with the class mates and the remote peers. In addition, the final output must be put in electronic form so as to be shared with all the participants in the 3D space. Students interact via electronic forums and e-mail. A friendly, cultural competition in which students take part in team with remote partners goes through the whole length of the experience.

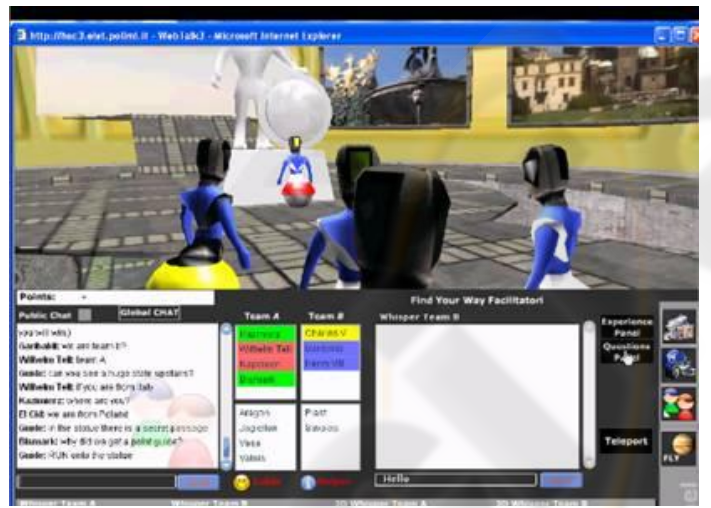

Figure 3: Learning@Europe. Users represented by avatars explore the virtual world and interact via chat. The environment is customized with the students' content (pictures of their own countries).

In this complex scenario the role of the teacher remains crucial but shifts to being that of a facilitator: she organizes the groups, checks that deadlines are met, monitors the students' proper behavior and the quality of the outcomes. This new role is determined by the fact that the experience is totally new to her, just like to her students.

\subsection{Technology}

The 3D environments are built using WebTalk 4 (by HOC), an architecture developed with Macromedia Studio 2004 MX that allows a high level of flexibility and programmability of the 3D contents and environments (Barbieri et al., 2006). It is based on XML metadata describing not only the scenes but also the modalities of interaction among the objects, the scenes and the users. Thus the educational experiences can be easily customized.

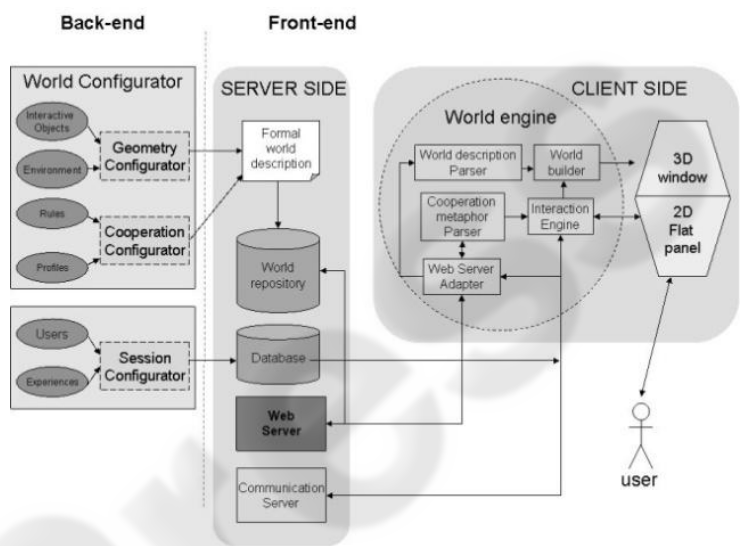

Figure 4: WebTalk4 architecture.

The architecture is based on a client/server paradigm: an application server hosts static and dynamic contents, a communication server (Macromedia Flashcomm) shares data in cooperative and distributed applications. The client is composed by a Schockwave plug-in that runs inside a regular internet browser (both are likely to be already installed in the user's system). These technological choices are all in view of a large-scale deployment of the program.

\subsection{Educational Benefits}

The above experiences are at the same time exciting and effective from an educational perspective (Di Blas, Poggi, 2008). Interacting with remote peers in a 3D environment, taking part together in a competition, etc. is definitely involving per se. A teacher reported that "when the online tutor declared us winners, students roared as if they had been at a soccer match" and another said that "students were so involved that it was difficult to calm them down". For the sake of the present argument we shall concentrate here on the less traditional benefits 
achieved by the students, making reference to the Learning@Europe project (the one that has involved the largest number of participants). For more details, the reader can find in the project's website the final reports as well as all the raw data collected (www.learningateurope.net). We carefully evaluated the program's impact by means of a complex apparatus of monitoring tools (Di Blas et al., 2008), including: (1) questionnaires to teachers before the experience and after each of the online sessions; (2) questionnaires to students before and after the experience; (3) surveys and semi-structured reporting by the online guides after each online sessions and - weekly - about the forums; (4) focus groups with a number of teachers at the end of each school year; (5) analysis of the students' artifacts (homework, forums' postings, chat...) and (6) videos shot in some selected classes. As we said above, traditional benefits (for example, related to increased knowledge of the subject matter) were reported and on the whole the overall educational impact was deemed high (fig. 6).

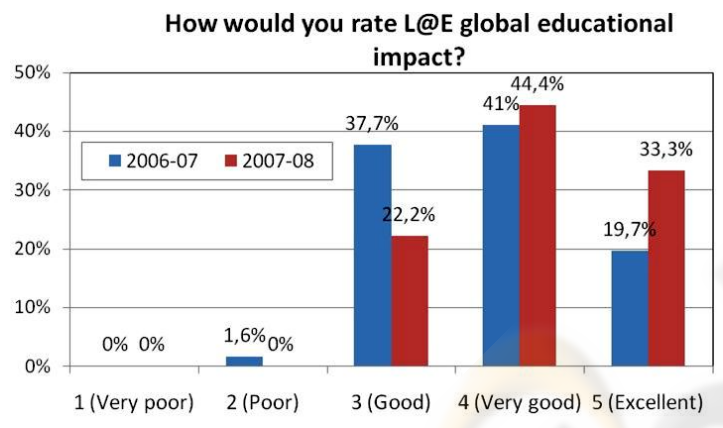

Figure 5: Teachers' rating of the overall educational impact of the Learning@Europe program (years 2006/07 and 2007/08; 70 respondents).

As regards less traditional benefits, they are mostly related to skills and attitudes. For example $68,8 \%$ of teachers rated their students' improvement in group work as very good and excellent (L@E, year 2007, 61 respondents). A junior high school teacher reported that one of her pupil who had come to visit her one year after the experience (the girl had moved to high school) complained about the fact that her new class-mates were not good at working in groups. Then she added "but you know, they had not 'done the Scrolls' (reference to the SEE project, about the Dead Sea Scrolls)". Another teacher interestingly remarked that their students had understood "that each one's contribution was crucial for the team's success" and that they were starting to understand "what a deadline is": an almost professional approach. It is remarkable that the experience (that dealt with European history in view of the formation of a sense of European identity) fostered a new attitude of tolerance and understanding towards other cultures. A student said: "now I understand that Europe is not just an idea, but something concrete", and another one quite naively noticed that "the Polish are like us". In addition, since the experience is usually rewarding, it generates a positive attitude towards school in general, fostering students' proficiency in all school's subjects. Last but not least, many teachers reported that the activity had rescued pupils with special needs, like not well integrated immigrants, disabled students etc. (Di Blas, Poggi, 2008).

\section{CASE 2: DIGITAL STORYTELLING}

In year 2005, we developed a toolkit, called 1001stories, for producing multimedia (audio, images, texts), multichannel (web, CD-rom, podcasts, cell phones...) "narrative" applications. The toolkit is very simple, consisting of a fixed information architecture (basically a set of main topics, each with a sub-set of details - see fig. 6), a pre-defined set of possible interactions for the user (with a preference for automatic navigation, where the application volunteers its content either in short or long format) and a specially-dedicated engine with a user-friendly interface that would allow teams of non techy-savvy developers to produce the "narratives". The toolkit has been used to produce 40 professional applications so far, on various topics ranging from the new printer by EPSON to the Roman Theater of Posillipo for the Ministry of Culture in Italy. Its simplicity almost immediately suggested to us the idea that it could also be used in school environments to allow students to use technology to communicate culture. The authoring environment is available online and the process requires only basic technological skills: creating text, creating (MP3) audio files, creating jpeg pictures, uploading files. The handling of the technological aspects, the deployment and the generation process, which would be more demanding from a technical standpoint, are left to the service provider, i.e. HOC-LAB. 1001stories seemed thus the perfect way to spread the "medialiteracy" (i.e. the ability "to effectively create, use and communicate information" using new technologies; US National Commission on Library and Information Science) that is so much sought 


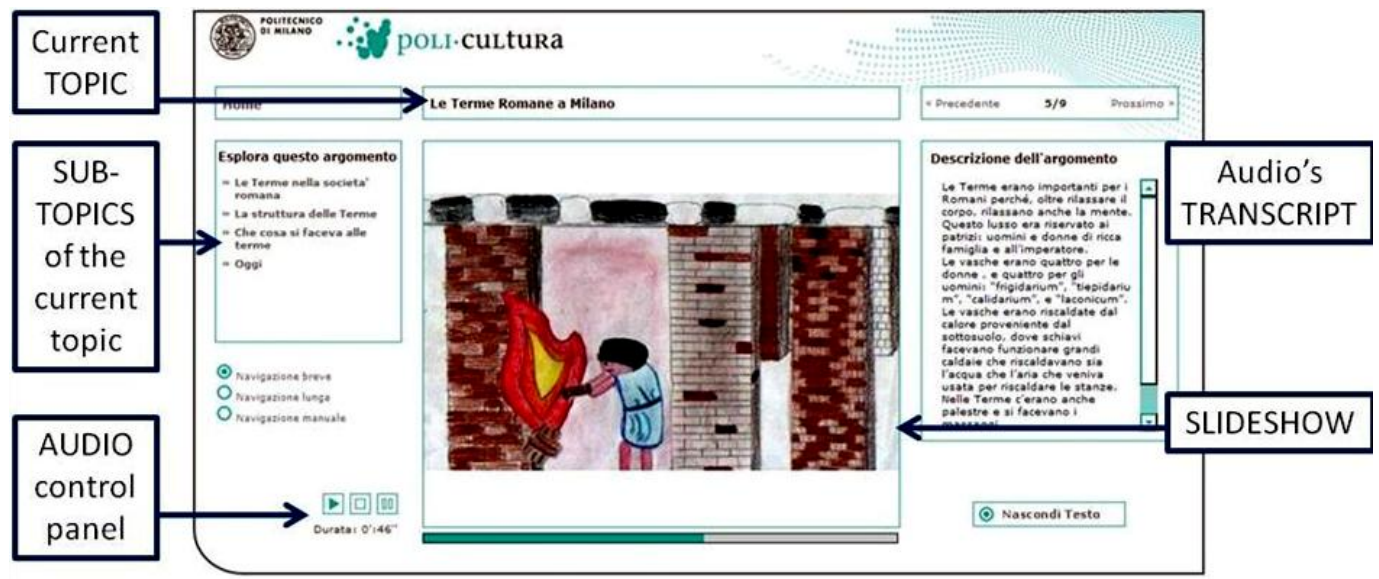

Figure 6: "Milan during the Roman Empire Age" (primary school). The screenshot shows how the final story looks: on the left, there is the list of sub-topics of the topic on display (the "Roman Baths of Milan" - as the title on top of the image reads). In the middle, a short slideshow of images runs ( 1 minute approximately) and eventually on the right there are the images' captions and the transcript of the audio comment.

after by school systems all over the world. Therefore, in year 2006, we launched the "PoliCultura" competition, inviting at first high school students, later on schools of all grades, including pre-school, to narrate their own local culture using our tool; more than 12,000 Italian students have used it so far.

\subsection{How the Activity Works}

Students taking part in a digital storytelling activity have to perform a number of activities. "Narrating" a story in digital form, with a specific tool, is not the same thing as writing it on paper. Once an overall theme is selected (like for example "Milan during the Roman Empire age" - fig. 6) it has to be split into topics, each on its turn with a set of sub-topics. This non-linear way of constructing a story is typical of interactive media and quite different from our (ex? Almost ex?) writing culture (Ong, 1982). Each topic and sub-topic is composed by: an audio (preferably lasting 1 minute approximately), a text available on demand (the audio's transcript) and a slideshow of images to go with the audio. Students thus have to learn how to write texts suitable for "audio-consumption" and also for "interactive consumption" (i.e. no previous content can be taken for granted like in a linear text - the user may 'come' from any part of the narrative). Images complement the narrative and make the final result pleasurable to see. In a word, using 1001stories students learn how to effectively communicate (about non trivial subjects) using a technological tool.

\subsection{Technology}

From a technological point of view, 1001stories is an engine, written in php, composed by 3 main parts: a Data Entry, a Preview and a Generator. The Data Entry is a simple authoring environment enabling the user to edit the editorial plan of the story and to enter content for each element. The Preview allows to visualize at any moment of the process the contents inserted that far, as they will appear to the final user. The Generator produces and publishes the final applications (for the different delivery channels).

\subsection{Educational Benefits}

In spite of the fact that we provide school with an agile set of guidelines on how to create an effective multimedia "narrative" (10/12 pages with hints ranging from how to record MP3 files to how to write the texts and select the images), the storytelling activity is much looser with respect to the 3D-based experiences described above. There are two main reasons: participants are free to select the narrative's theme (so content is up to them) and teachers monitor the whole experience (while in the 3D-based experiences they share the responsibility with the online tutors). We may also note that storytelling is a creative activity by definition, so it is no wonder that the final products are highly creative and "one different from the other" (Di Blas et al., 2009). But when we look at the benefits (monitored by means of online questionnaires to teachers), we find again that alongside with the tra- 
Table 1: Benefits related to the digital storytelling activity compared to achievements in regular school activities (year 2008-09, 153 respondents).

\begin{tabular}{|l|r|r|r|r|r|}
\hline \multirow{2}{*}{ Educational benefit } & \multicolumn{5}{|c|}{ Achievement with respect to regular teaching activities } \\
\cline { 2 - 6 } & 1[much lower] & 2[lower] & 3[equal] & 4 [better] & 5 [much better] \\
\hline Deep understanding & $0.00 \%$ & $0.70 \%$ & $4.60 \%$ & $\mathbf{5 4 . 6 0 \%}$ & $40.50 \%$ \\
\hline Content organization skills & $0.00 \%$ & $0.70 \%$ & $9.20 \%$ & $\mathbf{6 2 . 1 0} \%$ & $28.10 \%$ \\
\hline Retention & $0.00 \%$ & $0.70 \%$ & $5.90 \%$ & $39.50 \%$ & $\mathbf{5 4 . 2 0} \%$ \\
\hline Interest in a subject matter & $0.00 \%$ & $0.70 \%$ & $3.30 \%$ & $28.90 \%$ & $\mathbf{6 7 . 3 0} \%$ \\
\hline Engagement & $0.00 \%$ & $0.00 \%$ & $2.60 \%$ & $20.30 \%$ & $\mathbf{7 7 . 6 0 \%}$ \\
\hline Technical abilities & $0.00 \%$ & $1.30 \%$ & $8.50 \%$ & $35.90 \%$ & $\mathbf{5 4 . 6 0} \%$ \\
\hline Communication abilities & $0.00 \%$ & $0.00 \%$ & $7.90 \%$ & $\mathbf{5 1 . 0 0} \%$ & $41.40 \%$ \\
\hline Teamwork capacities & $0.00 \%$ & $0.00 \%$ & $6.60 \%$ & $38.20 \%$ & $\mathbf{5 4 . 9 0 \%}$ \\
\hline
\end{tabular}

ditional ones (e.g. increased knowledge of the subject matter) there are again the non-traditional ones, like increased media literacy and capacity of working in groups. All the teachers (67\% rating 5, and $33 \%$ rating 4 ) found that using 1001 stories had been a powerful tool for achieving "media literacy". Again, many interesting anecdotes about children with special needs being involved are there. A teacher said: "In my class there is a dyslexic kid. He tried to record his part 15, even 20 times and he did not want to give up. The whole class stood around him cheering and in the end he made it". Mentally disabled children strived to give their contribution in many of the narratives produced.

\section{RELATED WORKS}

Multi-User 3D Virtual Environments have become popular (also due to the success of Second Life) in a number of fields, and especially eEntertainment and eMarketing. They can also be used for Cultural Heritage, as for Kenderdine's Ancient Olympia, "Home of the Gods" (Kenderdine, 2001) and Johnson's Monticello, the home of Thomas Jefferson (Johnson, 2005), or the Theban Mapping Project (www.thebanmappingproject.com). It is less known, outside of a small circle of researchers and professionals, that they can also be used for education. Among the most known examples of virtual worlds for education are: Barab's Quest Atlantis (Barab et al., 2009; www.questatlantis.org), a persistent virtual world where children as young as 9 engage in curriculum-related quests to save an imaginary land from environmental disaster; Dede's River City, where teams of high school students investigate the social, health and environmental causes of an epidemic in a 19th virtual town (Dede et al., 2005); Bers' Zora, a virtual environment used by kids with psychological, mental or physical problems, who can find a way to express themselves and tell their stories by manipulating virtual objects and characters (Bers et al., 2005) and Wolf Quest, where users impersonate wild animals to learn about their life and habitat (Schaller et al., 2009). These projects can be categorized either as informal or formal education (most of the cultural heritage ones fall into the first category). Formal education, i.e. a situation where a group of pupils (possibly under the guidance of a teacher) have precise learning goals to be achieved with a well defined effort, has strong requirements to be met (such as organized groups of pupils, organized scheduling, limited time at disposal, possible conflicts with standard curricular activities, etc.). That characteristic may (for the time being) prevent their wide adoption. Still, we feel that 
the above introduced array of projects are quite promising for their creativity and show how technology can be exploited in an innovative way. In addition, when introduced in a real school environment, educational benefits comparable to the ones described in this paper are achieved, demonstrating the validity of the approach.

In the field of digital storytelling there are also many creative examples of programs aimed at fostering children's skills in "narrating" and/or taking part in a story. The benefits provided by introducing storytelling activities from early childhood have been widely discussed and demonstrated (Decortis and Rizzo, 2002; Madej, 2003; Kritzenberger, 2004; Richard and Williams, 2006) as well as the added value brought by technologies (Cassell and Ryokai, 2001). A number of authoring tools have been developed, like KidPad (Druin et al., 1997; Hourcade, 2002), a tool that involves children in synchronous co-presence collaborative story authoring, by using drawing, typing and hyperlinking functionalities optimized for synchronous collaborative input (e.g., multiple mice) on a 2-dimensional zoomable space. Further research has added tangible interface and gesture recognition technology to KidPad (Stanton et al., 2001), resulting in a "magic carpet" which can support collaboration in larger groups. Playful collaboration in the creation of stories is also explored in the projects StoryMat (Cassell and Ryokai, 2001; Ryokai and Cassell, 1999) and POGO (Decortis and Rizzo, 2002). Synchronous distancebased collaboration for authoring stories in 2D and 3D virtual environments has been exploited in projects such as FaTe2 (Garzotto and Forfori, 2006), MOOSE crossing (Bruckman, 1997) or MyStoryMaker (work in progress; McKinley and Lee, 2008). PUPPET (Marshall et al., 2002) is an example of a virtual environment used for teaching basics of drama production and enactment to children. An approach to narrative development which shifts the boundaries between author and user is Emergent Narrative (EN - Aylett, 1999), referring to stories in which the advancement of the narrative is determined by the interaction between characters, controlled by the user's choices. Eventually, StoryBuilder, produced by CBC4Kids (Canadian Broadcasting Corporation) is a web-based tool which enables children to create multimedia commix-style stories (Antle, 2003).

\section{CONCLUSIONS}

Innovative Learning Experiences, where technology is used for creating something otherwise impossible, are more challenging (from an instructional design point of view), but also more rewarding in a number of ways: they generate excitement and foster motivation; they can provide substantial (traditional and non-traditional) benefits; they better exploit all the - implicit - potential of technology. So far innovative eLearning experiences have been targeted more to schools' students rather than to higher education or corporate training (see the proceedings of conferences like eLearn or EDMEDIA to get the idea): we are currently investigating the possibility of transferring innovations also in these, for the time being more 'conservative', environments.

\section{ACKNOWLEDGEMENTS}

The case-studies discussed in this paper have been made possible by the great work of the HOC-LAB staff, the support of the rector of Politecnico (Prof. Giulio Ballio) and of the dean of the faculty of information technology engineering (Prof. Dino Mandrioli), the generous contribution of public and private organizations (especially the International Foundation of Accenture), and the scientific counseling of great learning scientists, among which we would like to especially thank Thomas Reeves (University of Georgia).

\section{REFERENCES}

Antle, A. (2003). Case study: the design of CBC4Kids' StoryBuilder. Proceedings of 2nd Int. Conf. on Interaction Design and Children, 59-68. ACM, NY.

Aylett, R. (1999). Narrative in Virtual Environments Towards Emergent Narrative. In: Mateas, M., Sengers P. (eds.) Narrative Intelligence. Papers from the 1999 Fall Symposium. Technical Report FS-99-01. 83-86. AAAI Press, Menlo Park, CA.

Barab, S., Gresalfi, M., Arici, A. (2009). "Why educators should care about games". Educational Leadership, Sept. 2009, 76-80.

Barchetti, U., Barbieri, T., Bucciero, A., Mainetti, L., Santo Sabato, S. (2006). WebTalk04: A Framework To Support 3D Collaborative E-Learning. The Fifth IASTED International Conference on Web-Based Education. Puerto Vallarta, Mexico, 23-25 January 2006, 13-18, ISBN/ISSN: 0-88986-541-8.

Bruckman, A. (1997). MOOSE Crossing: Construction, Community and Learning in a Networked Virtual 
World for Kids. Unpublished thesis, MIT, Cambridge, MA.

Cassell, J., Ryokai, K. (2001). Making Space for Voice: Technologies to Support Children's Fantasy and Storytelling. Personal and Ubiquitous Computing 5, 3, 169-190.

Decortis F., Rizzo A. (2002). New active tools for supporting narrative structures. Personal and Ubiquitous Computing, 6 (5-6), 416-429.

Dede, C., Clarke, J., Ketelhut, D., Nelson, B., Bowman, C. (2005). Students' Motivation and Learning of Science in a Multi-User Virtual Environment. Presented at AERA 2005

http://muve.gse.harvard.edu/muvees2003/documents/Dede _Games_Symposium_AERA_2005.pdf. Accessed Oct. 2009.

Di Blas, N., Bolchini, D., Paolini, P. (2007). Instant Multimedia: A New Challenge for Cultural Heritage. In: Bearman, D. \& Trant, J. (eds.) Museums and the Web 2007.

http://www.archimuse.com/mw2007/papers/diBlas/diBlas. html. Accessed October 7, 2009.

Di Blas, N., Boretti, B. (2009). Interactive storytelling in pre-school: a case-study. 8th Int. Conf. on Interaction Design and Children, 44-51. ACM, NY.

Di Blas, N., Garzotto, F., Paolini,P., Sabiescu, A. (2009). Digital Storytelling as a Whole-Class Learning Activity: Lessons from a Three-Years Project. Iurgel, I., Zagalo, N., Petta, P. (Eds.) Proceedings ICIDS 2009, Second International Conference on Interactive Digital Storytelling. Springer, Heidelberg (in press).

Di Blas, N., Garzotto, F., Poggi, C. (2009). Web Engineering at the frontiers of the Web 2.0: Design Patterns for online 3D Multiuser Spaces. In World Wide Web Journal, Springer

Di Blas, N., Poggi, C. (2008). Investigating Entertainment and Learning in a Multi-User 3D Virtual Environment, In Human-Computer Interaction Symposium (175188). Boston: Springer.

Druin, A., Stewart, J., Proft, D., Bederson, B., Hollan, J. KidPad (1997). A design collaboration between children, technologists, and educators. CHI'97, 463470. ACM, NY.

Garzotto, F., Forfori, M. (2006). FaTe2: storytelling edutainment experiences in $2 \mathrm{D}$ and $3 \mathrm{D}$ collaborative spaces. 5th Int. Conf. on Interaction Design and Children, 113-116. ACM, NY.

Hourcade, J. P., Bederson, B. B., Druin, A., Taxén, G. (2002). KidPad: collaborative storytelling for children. CHI 'O2 Extended Abstracts, 500-501. ACM, NY.

Johnson, B. (2005). Place-Based Storytelling Tools: A New Look at Monticello. D. Bearman and J. Trant (Eds), Museums and the Web 2005. Selected Papers from an International Conference. Toronto: Archives and Museums Informatics.

Kenderdine, S. (2001). 1000 Years of the Olympic Games: Treasures of Ancient Greece. Digital reconstruction at the home of the gods. Museums and the Web 2001. Selected papers from an international conference. Pittsburgh: Archives and Museum Informatics.
Klaebe, Helen G. Foth, M. (2006). Capturing Community Memory with Oral History and New Media: The Sharing Stories Project. 3rd International Conference of the Community Informatics Research Network (CIRN), 9 - 11 Oct, Prato, Italy.

Kritzenberger, H. (2004) Architectures for constructive multimedia learning environments: challenges for narrative teaching models. ED-MEDIA 2004, 88-95. AACE, Chesapeake, VA.

Lambert, J. (2006). Digital Storytelling. Capturing Lives, Creating Community. Digital Dinner Press, Berkeley, California.

Madej, K. (2003). Towards digital narrative for children: from education to entertainment, a historical perspective. Computers in Entertainment 1, 1, 1-17.

Marshall, P., Rogers, Y., Scaife, M. (2002). PUPPET: a Virtual Environment for Children to Act and Direct Interactive narratives. 2nd Workshop on Narrative and Interactive Learning Environments, Edinburgh, UK.

McKinley, B., Lee, Y. (2008). Mystorymaker. CHI '08 Extended Abstracts, 3219-3224. ACM, NY.

Meadows, D. (2003). Digital Storytelling: Research-Based Practice in New Media, Visual Communication 2; 189.

Meadows, D., Kidd, J. (2009). "Capture Wales": The BBC Digital Storytelling Project. In Hartley, J. and McWilliam, K. (Eds.) Story Circle. West Sussex, Blackwell Publishing.

Ong, W. (1982). Orality and Literacy: The Technologizing of the Word, London: Methuen.

Richard, C., Williams, D., Ma, Y. (2006). Implications of Narrative and Interactive Narrative for the Design of Problem-based Learning Environments. ED-MEDIA 2006, 2410-2414. AACE, Chesapeake, VA.

Ryokai, K. Cassell, J. (1999). StoryMat: a play space for collaborative storytelling. CHI '99 Extended Abstracts, 272-273. ACM, NY.

Sawhney, N. (2009) Voices Beyond Walls: The Role of Digital Storytelling for Empowering Marginalized Youth in Refugee Camps. IDC 2009, Workshop on Digital Technologies and Marginalized Youth, June 35, 2009, Como, Italy.

Schaller, D. et al. (2009). Learning In The Wild: What Wolfquest Taught Developers and Game Players. $J$. Trant and D. Bearman (eds). Museums and the Web 2009: Proceedings. Toronto: Archives \& Museum Informatics. Accessed October 7, 2009. http://www.archimuse.com/mw2009/papers/schaller/s challer.html.

Stanton, D., Bayon, V., Neale, H., Ghali, A., Benford, S., Cobb, S., Ingram, R., O'Malley, C., Wilson, J., Pridmore, T. (2001). Classroom collaboration in the design of tangible interfaces for storytelling. $\mathrm{CHI}$ '01, 482-489. ACM, NY.

US National Commission on Library and Information Science: The Prague Declaration: Towards an Information Literate Society (2003). http://www.infolit.org/international_conference_2003/ PragueDeclaration.pdf. Accessed October 7, 2009. 